\title{
Economic valuation of climate change-induced mortality: age dependent cold and heat mortality in the Netherlands
}

\author{
W. J. W. Botzen ${ }^{1,2}$ (D) M. L. Martinius ${ }^{3} \cdot$ P. Bröde ${ }^{4} \cdot$ M. A. Folkerts ${ }^{5} \cdot$ P. Ignjacevic ${ }^{1} \cdot$ \\ F. Estrada ${ }^{1,6} \cdot$ C. N. Harmsen ${ }^{7}$ - H. A. M. Daanen ${ }^{5}$
}

Received: 29 October 2019 / Accepted: 15 July 2020/Published online: 30 July 2020

(C) The Author(s) 2020

\begin{abstract}
This study examines the impacts of climate change on future mortality in the Netherlands and the related economic costs. Our methods account for changes in both cold- and heat-related mortality for different age classes, the time dynamics associated with temperature-related mortality, demographic change and the urban heat island effect. Results show that heat and cold impacts on mortality vary considerably between age classes, with older people being more vulnerable to temperature extremes. The sensitivity of mortality to temperature is higher on hot $\left(4.6 \% /{ }^{\circ} \mathrm{C}\right.$ ) than cold $\left(2.1 \% /{ }^{\circ} \mathrm{C}\right.$ ) days for the most vulnerable group ( $\geq 80$ years), and extreme temperatures have long time lags on mortality, especially in the cold. A main finding is that climate change is expected to first decrease total net mortality in the Netherlands due to a dominant effect of less cold-related mortality, but this reverses over time under high warming scenarios, unless additional adaptation measures are taken. The economic valuation of these total net mortality changes indicates that climate change will result in net benefits of up to $€ 2.3$ billion using the Value of a Statistical Life Year and $€ 14.5$ billion using the Value of a Statistical Life approaches in 2050, while this changes over time in net economic costs under high warming scenarios that can reach up to $€ 17.6$ billion in 2085. Implementing adaptation policies that reduce the negative impacts of warming on mortality in the heat can turn these net costs into net benefits by achieving a continued dominating effect of reduced mortality in the cold.
\end{abstract}

Keywords Climate change $\cdot$ Climate-induced mortality $\cdot$ Cold stress $\cdot$ Economic valuation $\cdot$ Heat stress $\cdot$ Health

Electronic supplementary material The online version of this article (https://doi.org/10.1007/s10584-02002797-0) contains supplementary material, which is available to authorized users.

W. J. W. Botzen

wouter.botzen@vu.nl

Extended author information available on the last page of the article 


\section{Introduction}

Climate change is projected to increase the frequency and severity of heat stress in many regions around the world (IPCC 2013). Temperature rise as a result of climate change is expected to have major implications for human health and for mortality in particular (Patz et al. 2005; IPCC 2014). It has been estimated that these impacts on health can have large economic costs (e.g. Stern 2007). For instance, Watkiss and Hunt (2012) estimate that the temperature-induced mortality effects can cost up to $€ 100$ billion annually by the end of this century for Europe only. Like most of the related literature, this estimate of economic impacts has been derived by valuing physical estimates of mortality changes with the Value of a Statistical Life (VOSL) and the Value of a Statistical Life Year (VOLY). Although estimates of mortality changes from temperature rise are commonly represented in models that estimate the economic impacts from climate change, like Integrated Assessment Models, it has been argued that these estimates are outdated and that more detailed empirical studies are needed about temperature-related mortality in particular areas (Huber et al. 2017).

The effects of climate change on mortality are complex and may also have economic benefits. On the one hand, temperature rise is expected to decrease cold-related mortality, while temperature rise increases mortality during periods of heat. Moreover, weather-related mortality is a dynamic process which is associated with long time lags. Extreme temperature conditions may have delayed effects on mortality rates up to several weeks after they occur, especially in the cold. Moreover, increased mortality may even be partly offset by reduced mortality at a later point in time, an effect known as harvesting. The total effect of climate change on mortality varies per region (Longden 2019) and is dependent, among other factors, on the sensitivity of mortality in cold and hot periods, the number of cold and hot days in a year and how this changes as a result of climate change, and the expected future temperature rise (Mills et al. 2015). In urban areas, the latter is influenced not only by the global warming but also by the urban heat island effect which refers to the additional heat in cities caused by the conversion of natural land to built-up areas that absorb more heat (Zhao et al. 2014). Moreover, mortality changes as a result of climate change depend on population change. For example, an ageing future population implies that more older people are exposed to heat stress, while this older segment of the population is especially vulnerable to heat (Baccini et al. 2008).

This study aims to obtain insights into the potential impacts of climate change on mortality and the related economic costs, while accounting for changes in both cold and heat-related mortality for different age classes, the time dynamics associated with temperature-related mortality, demographic change and the urban heat island effect. Our focus is on the Netherlands which currently experiences more cold than heat-related mortality, which may change under severe scenarios of climate change.

Our study contributes to an expanding literature that has estimated the impacts of weather on mortality, and, in some cases, assess the economic costs of mortality impacts from climate change. Deschênes and Moretti (2009) use daily data to estimate the effect of heat and cold on mortality for different age classes in the USA, and account for time lags in their regression analysis. They find that both extremely cold and extremely hot temperatures increase mortality. Deschênes and Greenstone (2011) use yearly mortality data for age classes in the USA which are related to the counts of days on which average temperature exceeds a certain 
threshold, and extrapolate the estimated relationships under climate change scenarios. The main finding of that study is that "business as usual" climate predictions indicate that by the end of the century, climate change will lead to an increase of the age-adjusted mortality rate by 3\%. Barreca (2012) uses monthly mortality data of the US population to estimate relations with the fractions of days on which average temperature and humidity exceed a certain threshold, which are used for extrapolation under a climate change scenario. The main outcome of that study is that mortality rates are likely to fall by $0.1 \%$ on the aggregate in the USA by the end of this century, and that hot and humid areas, like the South, will experience an increase in mortality rates, while cold and dry areas, like the North, will see a decline in mortality rates. Sheridan et al. (2012) assess how heat-related mortality may change in California by estimating empirical relationships between mortality in different age classes and weather types, and extrapolating these relationships under scenarios of climate and population change. They find that a 10-fold increase in mortality may occur in the age group older than 65 years in urban centers, and highlight the importance of accounting for demographic change in the extrapolations. A study with a related approach for Texas that examined mortality changes under climate and population change scenarios also concluded that demographic change, and in particular, ageing of the population increases the risks of mortality from temperature increases (Marsha et al. 2018). Otrachshenko et al. (2017) estimate how yearly mortality for different age groups in Russia is related to the fraction of days on which average temperature and precipitation exceed a certain threshold. The estimated relationships are used for an illustrative extrapolation of a 1 day with hot and cold temperatures that is valued in economic terms using the value of the forgone earnings of a death in the working class population. They find that both hot and cold days cause an increase in mortality, and that the economic costs due to 1 day with either hot or cold temperatures correspond to 10.25 million USD and 7.91 million USD, respectively.

Our study builds upon Daanen et al. (2013) who make a first attempt to estimate the impacts of climate change on mortality in the Netherlands for a constant population. This was done by extrapolating a non-linear regression model of mortality in the total population based on average temperature under climate change scenarios and the urban heat island effect, by assuming that the entire county is an urban area. Our approach advances upon this first attempt by: (i) using a temperature indicator from different weather stations in the Netherlands instead of one station to represent temperature conditions across the county; (ii) estimating separate regression models for mortality in different age classes to reflect age-varying vulnerability; (iii) estimating separate effects of temperature on mortality in the cold and heat that are related with different physiological processes causing mortality; (iv) accounting for time lags in temperature effects on mortality; (v) including the urban heat island effect only for the most urbanized part of the Netherlands; (vi) considering demographic changes, (vii) including population growth, ageing of the population and urbanization in estimating the impacts of climate change on mortality; and finally, (viii) by adopting a Dutch instead of a foreign VOSL value and by additionally valuing mortality impacts for different age classes using the VOLY. These changes result in several new insights. For instance, we find substantially larger economic impacts of mortality changes as a result of climate change. In particular, we do not only observe net benefits from reduced cold-related mortality, like in the first study, but we also identify scenarios under which net costs arise. Moreover, based on our models for different age classes, we obtain insights into heterogeneous effects of heat and cold stress and warming from climate change for different age groups and adjust our economic valuation accordingly. 


\section{Methods and data}

We used a constrained segmented distributed lag model to estimate the effects of temperature per day $t$ in heat or cold periods $i$ on mortality ratio $y_{t, i}$ (Muggeo 2008, 2010). The daily mortality ratio was estimated by dividing daily mortality with the population at that day multiplied by 100,000, so it yields the deaths per 100,000 inhabitants. This dependent variable was calculated separately for categories $c$ of the total population and three age classes for which we have separate mortality and population size data. The main regression specification which was estimated separately for the mortality ratios in the total population and different age classes is as follows:

$$
\log y_{t, i, c}=\beta_{0}+s(t ; n d t)+\gamma w_{t}+\sum_{l 1=0}^{L 1} \beta_{1 l_{1}}\left(z_{t-l 1}-\varphi\right)_{-}+\sum_{l 2=0}^{L 2} \beta_{2 l_{2}}\left(z_{t-l 2}-\varphi\right)_{+}+\varepsilon
$$

where following the Muggeo $(2008,2010)$ notation $(z-\varphi)_{-}=(z-\varphi) I(z<\varphi)$ and $(z-\varphi)_{+}=(z$ $-\varphi) I(z>\varphi)$ are two linear spline functions which allow to estimate the effects of low and high temperatures, respectively below and above threshold $\varphi$. Here, $\varphi$ equals $16.3{ }^{\circ} \mathrm{C}, 15.1{ }^{\circ} \mathrm{C}$, $17.5^{\circ} \mathrm{C}$ and $17.4^{\circ} \mathrm{C}$, respectively, for the total population and age classes $<65$ years, 65 80 years and $\geq 80$ years. These $\varphi$ values were estimated to be the optimal temperature levels for these population groups in our data, meaning it results in the lowest daily mortality, which is called the mean minimum mortality temperature (MMT). $L_{1}$ and $L_{2}$ are the maximum number of lags to estimate the delayed mortality effects of cold and heat, which were set at 60 for cold and 30 for heat for which temperature impacts are found to be less persistent. $w_{t}$ is a vector of dummy variables of the day of the week which were included as control variables. The function $s(t ; n d t)$ denotes a B-spline of rank $n d t$ allowing to model the long-term trend and seasonality in a non-parametric way (Muggeo 2010). We used the spline function with $n d t=30$, which resulted in a better model fit ${ }^{1}$ than including parametric terms for month and a daily and yearly time trend. Although a non-linear relationship between mortality and temperature at the extremes is found in other regions (Deschênes and Greenstone 2011), previous research has shown that the linear V-shaped relationship assumed by our model appropriately describes the mortality-temperature relationship for the Netherlands (Kunst et al. 1993; Huynen and Martens 2015). These results can be reconciled with Deschênes and Greenstone (2011) who for the USA find a fairly linear temperature-mortality relationship for cold and warm days, with the exception at the 'extreme' mean daily temperatures exceeding $90{ }^{\circ} \mathrm{F}$ (i.e. $32^{\circ} \mathrm{C}$ ). However, in our data, the highest value for average daily temperature was $26.8^{\circ} \mathrm{C}$, which means that our temperature observations fall within the range for which Deschênes and Greenstone (2011) find fairly linear temperature-mortality relationships.

Our main parameters of interest are $\beta_{1}$ and $\beta_{2}$ which capture the total effects of temperature, integrated over the actual and lagged periods, in the cold and heat on the log mortality ratio. More precisely, according to the Muggeo (2008, 2010) notation, $\beta_{1}=\left(\beta_{10}\right.$, $\left.\beta_{11}, \ldots, \beta_{1 l_{1}}, \ldots, \beta_{1 L_{1}}\right)^{\mathrm{T}}$ is the lag specific log relative risk of a one unit decline in temperature below the threshold, and $\beta_{2}=\left(\beta_{20}, \beta_{21}, \ldots, \beta_{2 l_{2}}, \ldots, \beta_{2 L_{2}}\right)^{\mathrm{T}}$ is the lag specific log relative risk for a one unit increase in temperature greater than the threshold $\varphi$. These coefficients can be interpreted as semi-elasticities of the percentage change in the mortality ratio that results from a unit change in temperature since the dependent variable is in log and temperature in levels.

${ }^{1}$ This was judged using the Bayesian Information Criterion (BIC). 
The model was estimated in the statistical software $\mathrm{R}$ using the package modTemEff developed by Muggeo $(2008,2010)$. We report the 'bayesian' standard errors of $\beta_{1}$ and $\beta_{2}$. The data used are on a daily level between January 1, 1995 and December 31, 2017, and have been obtained as follows. Mortality data was obtained from Statistics Netherlands (in Dutch Centraal Bureau voor de Statistiek; CBS). This mortality data includes the daily number of allcause mortality for the total Dutch population, and a subdivision of this mortality data for three age classes: $<65$ years, $65-80$ years and $\geq 80$ years. Moreover, data on daily population size in the Netherlands was obtained from the CBS. ${ }^{2}$ Using data from the Royal Netherlands Meteorological Institute (in Dutch Koninklijk Nederlands Meteorologisch Instituut; KNMI), an average daily temperature variable in ${ }^{\circ} \mathrm{C}$ was created based on hourly temperature records of the five main weather stations in the Netherlands, by averaging over time and space. ${ }^{3}$

The parameter estimates of $\beta_{1}$ and $\beta_{2}$ were used to project how average daily mortality on cold and warm days is expected to change under climate change scenarios. For this analysis, we used climate change projections that have been made for the Netherlands by the KNMI (Klein Tank et al. 2014). These projections are based on an ensemble of Global Circulation Models that represent a wide range of uncertainties in climate system response and translate the outcomes on global climate change of the IPCC (2013) to the Netherlands. Projections were made for four scenarios that provide a realistic picture of how the climate in the Netherlands will look like around the year 2050, which is a representative for climate in the period 2036-2065, and the year 2085, which is representative for the period 2071-2100. ${ }^{4}$ These scenarios include the following: a moderate $(\mathrm{G})$ and a warm scenario (W) in which global average temperature increases by $1{ }^{\circ} \mathrm{C}$ and $2{ }^{\circ} \mathrm{C}$, respectively; and corresponding 'plus' scenarios (+), in which atmospheric circulation changes in addition to the temperature change in a manner that westerly circulation is stronger in winter and easterly circulation is stronger in summer. These projections indicate that the average temperature is expected to increase by between $1.3{ }^{\circ} \mathrm{C}$ and $3.7{ }^{\circ} \mathrm{C}$ in the year 2085 (see Table 2).

Moreover, we present mortality projections separately for additional warming in urban areas due to the urban heat island effect under these four climate change scenarios. This is done by accounting for the average additional warming in the main urbanized area in the Netherlands called the Randstad, which primarily consists of the four largest cities in the Netherlands: namely, Amsterdam, Rotterdam, The Hague and Utrecht and surrounding areas. ${ }^{5}$ The reasons for focusing on the Randstad is that it is the main urbanized area in the Netherlands with a population density of $1500 / \mathrm{km}^{2}$, and a population size that for example is comparable with the Milan metropolitan area in Italy. Moreover, for this area, we could obtain both estimates of future demographic change under socio-economic scenarios (described below) and additional warming from the urban heat island effect. The latter is obtained from an approach used by

\footnotetext{
${ }^{2}$ Population data is available on a yearly interval between 1995 and 2002 and afterwards on a monthly interval. Linear interpolation was applied to create a daily time series of this variable.

${ }^{3}$ Temperature data was obtained from the following five weather stations which together are indicative for weather conditions for the Netherlands: De Bilt; Rotterdam; Schiphol Airport; Eelde and Maastricht.

${ }^{4}$ These scenarios cannot be directly linked to the RCP scenarios used by the IPCC. Nevertheless, a comparison has been made in Klein Tank et al. (2014) which shows that the G scenarios are close to the temperature rise in the RCP2.6 scenario and correspond to the lower uncertainty bound of the RCP4.5 and RCP6.0 scenarios, while the W scenarios match the high RCP8.5 scenario.

${ }^{5}$ The main cities in the Randstad are: Amsterdam, Almere, Utrecht, Rotterdam, Leiden, Den Haag, Amersfoort, Dordrecht, Hilversum and Haarlem.
} 
Estrada et al. (2017) who assess additional warming from the urban heat island effect using an empirical relation of average temperature rise based on population as a proxy for urbanization. ${ }^{6}$ Using this method, the average additional local warming in the Randstad area is calculated, which is added to the warming under the KNMI climate change scenarios for the analysis that accounts for the urban heat island effect.

The mortality projections are made under each climate scenario denoted with $s$ using the following steps. The temperature change in each scenario $\left(\Delta T_{t, s}\right)$ is multiplied with the parameter estimates of $-\beta_{1}$ or $\beta_{2}$. The negative of $\beta_{1}$ is used since this coefficient represents the effect on the mortality ratio of a $1{ }^{\circ} \mathrm{C}$ lower temperature, while we examine effects of warming. This gives the expected percentage change in the daily mortality ratio in the cold $\left(-\beta_{1} \times \Delta T_{t, s}\right)$ or heat $\left(\beta_{2} \times \Delta T_{t, s}\right)$ under a warming scenario, which are subsequently multiplied with the average daily mortality ratio $\left(y_{t, i, c}\right)$ in the cold or heat in our sample period that we view as being representative for mortality under the current climate. These calculations are made separately for the different $\Delta T_{t, s}$ values under the four climate scenarios that include or exclude the urban heat island effect. This procedure implies that we assume that climate change causes a shift by $\Delta T_{t}$, $s$ in the temperature distribution, while we do not account for changes in the shape of the distribution, such as more than average warming on extremely hot days. This assumption could especially affect results if the temperature-mortality relationship is non-linear at the extremes, but this is less of a concern in our study for the Netherlands where this relationship is adequately described through a linear V-shaped function as was discussed above. These calculations arrive at the absolute change in the daily average mortality ratio in the cold or heat under these scenarios. These changes in the average daily mortality ratios in the cold $\left(\Delta y_{t,-, c, s}\right)$ and heat $\left(\Delta y_{t,+, c, s}\right)$ are estimated separately for the years 2050 and 2085 and for the different estimates of Eq. 1 for mortality in the total population and the three age classes. To estimate the change in the absolute number of daily deaths from climate change in the cold $\left(\Delta d_{t,-, c, s}\right)$ and heat $\left(\Delta d_{t,+, c, s}\right)$, these changes in mortality ratios are multiplied with the population $P O P_{t, c}$ per 100,000 people in the future time periods 2050 and 2085. Formally, for the projections excluding the urban heat island effect, this can be expressed as:

$$
\begin{gathered}
\Delta d_{t,-, c, s}=\Delta y_{t,-, c, s} \times P O P_{t, c} \\
\Delta d_{t,+, c, s}=\Delta y_{t,+, c, s} \times P O P_{t, c}
\end{gathered}
$$

The projections including the urban heat island effect depend on the fractions of the population living in the urbanized Randstad area $\lambda_{t}$ or outside this area $\left(1-\lambda_{t}\right)$ for which $\Delta y_{t,-, c, s}$ and $\Delta y_{t,+, c, s}$ differ due to different warming scenarios $s$ :

$$
\Delta d_{t,-, c, s}=\Delta y_{t,-, c, s} \times \lambda_{t} t P O P_{t, c}+\Delta y_{t,-, c, s} \times\left(1-\lambda_{t}\right) P O P_{t, c}
$$

\footnotetext{
${ }^{6}$ The increases in urban temperature for cities with 100,000 inhabitants or more are approximated using empirical relationships of the form $a * P o p^{b}$, where $P o p$ represent the urban population, and $a, b$ are fixed parameters, which is a functional form that has been used by a variety of studies (Oke 1973; Karl et al. 1988; Mills 2014). As in Estrada et al. (2017), we set to $b=0.45$ and $a=1.74^{*} 10^{-3}$ based on a calibration by Karl et al. (1988)
} 


$$
\Delta d_{t,+, c, s}=\Delta y_{t,+, c, s} \times \lambda_{t} t P O P_{t, c}+\Delta y_{t,+, c, s} \times\left(1-\lambda_{t}\right) P O P_{t, c}
$$

Finally, these daily changes in number of deaths are translated into changes in the total yearly number of deaths by multiplying $\Delta d_{t,-, c, s}$ with the average number of cold days in a year under the climate change scenario, and adding the multiplication of $\Delta d_{t,+}, s, s$ with the average number of heat days in a year under the climate change scenario. Supplementary Material 1 describes how our values of $P O P_{t, c}$ and $\lambda_{t}$ in the years 2050 and 2085 are derived from the WLO (in Dutch Welvaart en Leefomgeving) scenarios which are the most detailed socioeconomic scenarios for the Netherlands that are consistent with the global and longer term Shared Socio-Economic Pathways (SSP) scenarios (Manders and Kool 2015). These scenarios are defined in our study as POP-low, which is characterized as low migration to the Netherlands, weak rise in life expectancy, and low fertility and POP-high which is characterized as high migration to the Netherlands, strong rise in life expectancy, and high fertility.

A final methodological step is to value the projected changes in mortality as a result of climate change in monetary units. The yearly expected future changes in mortality are valued in economic terms using the VOSL for the Netherlands. In addition to using the VOSL, the mortality changes that are derived from the models with the mortality data for the three age classes are valued with the VOLY, and the expected life years lost. The VOLY approach gives relatively lower values to mortality of people with a lower remaining life expectancy, while the VOSL approach values mortality in all age classes equally. As described in Supplementary Material 2, the VOSL and VOLY values for the Netherlands are derived from Van Gils et al. (2014).

\section{Results}

\subsection{Results of statistical models}

Table 1 shows the main regression results for our models based on the mortality ratio for the total population and three age classes. The reported coefficients of the total effects of heat and cold stress, namely the betas integrated over all lag periods, are highly statistically significant ( $p$ value $<0.01)$ in the model for the total population. The total effect of cold stress, meaning a $1{ }^{\circ} \mathrm{C}$ lower temperature below the cold threshold, is an increase in the mortality ratio of about $1.5 \%$ for the total population. In other words, if climate change would increase temperature on cold days with $1{ }^{\circ} \mathrm{C}$, then this decreases the mortality ratio with approximately $1.5 \%$ on cold days. The results for this coefficient differ substantially between the three age classes. The effect of cold stress is not significant at the $5 \%$ level for age class $<65$, which confirms that only older people are vulnerable to temperature-related mortality. The effect of cold stress is significant for the two highest age classes and increases with age. The total effect of heat stress, meaning a $1{ }^{\circ} \mathrm{C}$ higher temperature above the heat threshold, is an increase in the mortality ratio of $1.6 \%$ for the total population. The results for this coefficient differ per age class in a way that the effect is close to zero and insignificant for the lowest age class $(<65)$, while the effect is significant for age class $65-80$ and substantially larger for age class $\geq 80$. In particular, a $1{ }^{\circ} \mathrm{C}$ higher temperature above the heat threshold results in an increase in the mortality ratio of approximately $4.6 \%$ for people that are 80 years or older. The sensitivity of mortality to temperature for this vulnerable older age group is much higher on hot than cold days. The dynamic effects of cold and heat stress on the mortality ratio are illustrated in S-Figs. 3.1-3.4 
Table 1 Regression model results of effects of cold and heat stress on mortality for the total sample and three age classes

\begin{tabular}{lllll}
\hline & Total population & Age class $<65$ & Age class 65-80 & Age class $\geq 80$ \\
\hline Total effect of cold stress $\beta_{1}$ & 0.01519 & 0.00431 & 0.01212 & 0.02088 \\
Standard error $\beta_{1}$ & 0.00200 & 0.00275 & 0.00103 & 0.00054 \\
Total effect of heat stress $\beta_{2}$ & 0.01597 & $7.840 \mathrm{e}-10$ & 0.01634 & 0.04594 \\
Standard error $\beta_{2}$ & 0.00773 & $4.466 \mathrm{e}-06$ & 0.00644 & 0.00519 \\
Number of observations (days) & 8341 & 8341 & 8341 & 8341 \\
\hline
\end{tabular}

Coefficients of control variables are suppressed for brevity

in Supplementary Material 3. These results show that effects of cold stress persist longer in time than for heat stress. Moreover, the observed long-lasting effects on mortality that sometimes only dissipates after 40 days illustrate the importance of accounting for the lag structure, like we do in our models.

\subsection{Projected mortality changes as a result of climate change without adaptation}

Table 2 shows the mortality projections under the four KNMI climate change and socioeconomic scenarios for the years 2050 and 2085, without accounting for additional warming

Table 2 Projections of daily changes in heat and cold-related mortality as a result of climate change for the years 2050 and 2085 under different climate and socio-economic scenarios, and total net yearly mortality with, and without accounting for additional warming from the urban heat island (UHI) effect

\begin{tabular}{|c|c|c|c|c|c|c|c|c|}
\hline \multirow{3}{*}{$\begin{array}{l}\text { Climate change } \\
\text { scenario } \\
\text { Socio-economic } \\
\text { scenario }\end{array}$} & \multicolumn{4}{|c|}{ Year 2050} & \multicolumn{4}{|l|}{ Year 2085} \\
\hline & G & G+ & W & $\mathrm{W}+$ & G & $\mathrm{G}+$ & W & $\mathrm{W}+$ \\
\hline & $\begin{array}{l}\text { POP- } \\
\text { high }\end{array}$ & $\begin{array}{l}\text { POP- } \\
\text { high }\end{array}$ & $\begin{array}{l}\text { POP- } \\
\text { low }\end{array}$ & $\begin{array}{l}\text { POP- } \\
\text { low }\end{array}$ & $\begin{array}{l}\text { POP- } \\
\text { high }\end{array}$ & $\begin{array}{l}\text { POP- } \\
\text { high }\end{array}$ & $\begin{array}{l}\text { POP- } \\
\text { low }\end{array}$ & $\begin{array}{l}\text { POP- } \\
\text { low }\end{array}$ \\
\hline Temperature rise $\left({ }^{\circ} \mathrm{C}\right)$ & 1.0 & 1.4 & 2.0 & 2.3 & 1.3 & 1.7 & 3.3 & 3.7 \\
\hline \multicolumn{9}{|c|}{ Cold impacts in terms of the change in number of deaths per day for } \\
\hline Total population & -7 & -10 & -12 & -13 & -9 & -12 & -15 & -17 \\
\hline Age class $<65$ & 0 & 0 & -1 & -1 & 0 & 0 & -1 & -1 \\
\hline Age class $65-80$ & -3 & -4 & -5 & -6 & -3 & -5 & -7 & -8 \\
\hline Age class $\geq 80$ & -8 & -11 & -14 & -16 & -37 & -49 & -43 & -48 \\
\hline \multicolumn{9}{|c|}{ Heat impacts in terms of the change in number of deaths per day for } \\
\hline Total population & 7 & 10 & 12 & 14 & 9 & 12 & 15 & 17 \\
\hline Age class $<65$ & 0 & 0 & 0 & 0 & 0 & 0 & 0 & 0 \\
\hline Age class $65-80$ & 4 & 6 & 7 & 8 & 4 & 6 & 9 & 10 \\
\hline Age class $\geq 80$ & 17 & 24 & 29 & 33 & 78 & 102 & 90 & 101 \\
\hline \multicolumn{9}{|c|}{ Total net impacts without the UHI in terms of the change in number of deaths per year for } \\
\hline Total population & -1191 & -1457 & -1515 & -1545 & -1471 & -1658 & -1191 & -1087 \\
\hline Age class $<65$ & -76 & -103 & -120 & -133 & -84 & -106 & -120 & -130 \\
\hline Age class $65-80$ & -655 & -843 & -851 & -876 & -666 & -795 & -651 & -596 \\
\hline Age class $\geq 80$ & -1127 & -1322 & -993 & -783 & -4765 & -4587 & 310 & 1442 \\
\hline Total age classes & -1858 & -2269 & -1964 & -1792 & -5515 & -5488 & -461 & 716 \\
\hline \multicolumn{9}{|c|}{ Total net impacts with the UHI in terms of the change in number of deaths per year for } \\
\hline Total population & -1486 & -1676 & -1555 & -1583 & -1687 & -1802 & -1003 & -912 \\
\hline Age class $<65$ & -81 & -107 & -121 & -137 & -88 & -109 & -128 & -142 \\
\hline Age class $65-80$ & -825 & -923 & -853 & -872 & -773 & -852 & -589 & -504 \\
\hline Age class $\geq 80$ & -1141 & -1134 & -657 & -317 & -3996 & -3303 & 1868 & 3273 \\
\hline Total age classes & -2047 & -2165 & -1630 & -1326 & -4856 & -4264 & 1151 & 2627 \\
\hline
\end{tabular}


from the urban heat island effect. The projected changes in daily mortality are shown separately for hot and cold days and are the outcome of a higher average temperature on those days. These estimates should be interpreted as the change in mortality that is caused by climate change in these future years given the exposed population at that time, compared with a situation in which no climate change occurs. Depending on the climate change scenario, cold mortality is expected to decline with between 7 and 13 deaths per day in the year 2050 and between 9 and 17 deaths per day in the year 2085, based on the model for the total population. The sum of reduced deaths based on the models of the three age classes is almost twice as large in 2050 and higher afterwards, which shows that the model for the total population underestimates reduced future mortality in the cold. The results per age class show that the number of lives saved in the age class $65-80$ is smaller compared with lives saved in the highest age class $\geq 80$. The increase in heat mortality for the total population is close to the reduced mortality in the cold for that model, but it is higher than reduced mortality in the cold for the different age class models. In particular, the increase in mortality on hot days is much higher than the reduced mortality on cold days for the most vulnerable oldest age group. Reduced mortality in the cold for the age class $\geq 80$ is at maximum 16 lives saved per day in 2050 and 48 per day in 2085, while additional deaths in the heat for this age class are at maximum 33 per day in 2050 and 101 per day in 2085. These findings illustrate the importance of the differentiation of mortality according to age classes for capturing different sensitivity to temperature changes in the cold and heat.

The observation that the number of additional deaths due to climate change on hot days outweighs the number of reduced deaths on cold days does not necessarily mean that total mortality in a year increases due to climate change, because the number of cold days in a year exceeds the number of hot days in the Netherlands. The projected annual mortality changes are the combined outcomes of the increase in average temperature per day, as well as the decrease in cold days to which the cold stress mortality curve is applied and an analogous increase in hot days to which the heat stress mortality curve is applied. In particular, the percentage of cold days $(T<\varphi)$ decreases under the climate change scenarios. This is illustrated in S-Table 4.1 in Supplementary Material 4 which shows the percentage of cold and hot days to which respectively the cold and heat stress mortality curves are applied, which differs per model due to varying $\varphi$ (see methods) and per climate change scenario.

In addition to the projected daily changes in mortality that are shown separately for cold and hot days, Table 2 reports net mortality changes per year to illustrate which effect dominates and to show when more mortality in the heat may offset reduced mortality in the cold. This information may contribute to raising awareness about this climate change risk in the Netherlands, where first attempts to research this topic have found a dominating effect of climate change reducing mortality in the cold (Daanen et al. 2013). Up to the year 2050, we observe that the effect of climate change on net annual mortality is that total yearly mortality declines in the model for the total population, but this decline is smaller under the scenarios with high warming ( $\mathrm{W}$ and $\mathrm{W}+$ ) based on the age class models. This pattern of decline in mortality is smaller for age class $<65$ than the older age classes $65-80$ and $\geq 80$. For the year 2085 , we observe that the decline in total yearly mortality still occurs in the low climate change scenarios ( $\mathrm{G}$ and $\mathrm{G}+$ ) and the higher scenario W. In contrast, in the highest climate change scenario (W+), mortality increases substantially up to 716 additional deaths per year for the sum of the three age class models. A general pattern is that the model for the total population underestimates both declines in mortality under the low warming scenarios, and does not predict the increase in mortality under the highest warming scenario. For the different age classes, it is observed that for age 
class $<65$, total annual mortality slightly declines under all scenarios and a substantially higher decline is observed for age class $65-80$. On the other hand, substantial net increases in mortality are observed for the highest age class $\geq 80$ years under the $\mathrm{W}$ and $\mathrm{W}+$ warming scenarios. An important conclusion is that in about 60 years from now, the dominance of reduced cold-related mortality from climate change will be replaced with more heat-related mortality if the W+ climate scenario materializes.

As a next step, we examine the effects on changes in mortality of accounting for additional warming that occurs under the climate change scenarios from the urban heat island effect in the urbanized Randstad area. The resulting projected daily mortality changes in the cold and the heat for the population outside, and inside, the urbanized Randstad area are shown in STable 5.1 in Supplementary Material 5. This table also reports the average temperature rise under each climate scenario with, and without the additional warming from the urban heat island. These projections illustrate that, due to additional warming, people in the urbanized Randstad area benefit more from reduced mortality in the cold compared with people outside this area, while they experience more increased mortality in the heat. The total additional daily mortality in the heat is higher than the total reduced mortality in the cold if the urban heat island effect is accounted for (S-Table 5.1), compared with not accounting for it (Table 2). The bottom part of Table 2 shows how these changes in daily mortality estimates translate into changes in net yearly mortality. The yearly mortality estimates also depend on the lower proportion of cold days (and higher proportion of heat days) experienced by people subject to the urban heat island effect (shown in S-Table 4.1 in Supplementary Material 4). Accounting for the urban heat island effect implies that in all scenarios except $\mathrm{G}$, where the total net yearly effect of mortality changes over the age classes is a decline in mortality, this reduction in mortality becomes smaller compared with not accounting for the urban heat island. Moreover, based on the different age class models, net increases in mortality can also occur under the $\mathrm{W}$ scenario and not only the $\mathrm{W}+$ when the urban heat island effect was not accounted for. The mortality increases in 2085 are substantially higher under these scenarios (up to 2627 deaths per year) than without accounting for the urban heat island effect (up to 716 deaths per year). Overall, these results illustrate the importance of accounting for the urban heat island effect in mortality projections under climate change scenarios.

\subsection{Economic valuation of climate change-induced mortality changes without adaptation}

Table 3 expresses the total yearly climate change-induced mortality changes that account for additional warming from the urban heat island effect in economic costs. These results are shown separately for using the VOSL or VOLY valuation methods. VOSL valuations based on the total population and the total of the age classes do arrive at the same sign, except for the $\mathrm{W}$ and $\mathrm{W}+$ scenario in 2085. Based on the total of the age class impacts, the results show net economic benefits in 2050 due to a dominant effect of less cold-related mortality for both valuation approaches. These net economic benefits in 2050 range between $€ 1.8$ billion and $€ 2.3$ billion using the VOLY and between $€ 8.8$ billion and $€ 14.5$ billion using the VOSL. The 2085 results show that net benefits under low warming scenarios turn into net costs for the highest warming scenario $\mathrm{W}+$. These net costs are $€ 109$ million using the VOLY and reach $€ 17.6$ billion using the VOSL valuation method. The second highest warming scenario $\mathrm{W}$ results in a net cost of $€ 7.7$ billion using the VOSL, while that scenario still results in net benefits when the VOLY is used. The observed pattern of initial net benefits of climate change 
Table 3 Net economic costs of mortality changes based on the models for the total population or specific age classes, in million euro losses per year for the years 2050 and 2085, accounting for additional warming from the urban heat island (UHI) effect and using the VOSL or VOLY valuation method (negative values are net benefits, positive values are net costs)

\begin{tabular}{|c|c|c|c|c|c|c|c|c|}
\hline \multirow{3}{*}{$\begin{array}{l}\text { Climate change } \\
\text { scenario } \\
\text { Socio-economic } \\
\text { scenario }\end{array}$} & \multicolumn{4}{|c|}{ Year 2050} & \multicolumn{4}{|l|}{ Year 2085} \\
\hline & G & G+ & $\mathrm{W}$ & $\mathrm{W}+$ & G & G+ & $\mathrm{W}$ & $\mathrm{W}+$ \\
\hline & $\begin{array}{l}\text { POP- } \\
\text { high }\end{array}$ & $\begin{array}{l}\text { POP- } \\
\text { high }\end{array}$ & $\begin{array}{l}\text { POP- } \\
\text { low }\end{array}$ & $\begin{array}{l}\text { POP- } \\
\text { low }\end{array}$ & $\begin{array}{l}\text { POP- } \\
\text { high }\end{array}$ & $\begin{array}{l}\text { POP- } \\
\text { high }\end{array}$ & $\begin{array}{l}\text { POP- } \\
\text { low }\end{array}$ & $\begin{array}{l}\text { POP- } \\
\text { low }\end{array}$ \\
\hline \multicolumn{9}{|c|}{ Net costs based on the VOSL } \\
\hline Total population & -9958 & $-11,229$ & $-10,418$ & $-10,604$ & $-11,306$ & $-12,073$ & -6719 & -6108 \\
\hline Age class $<65$ & -544 & -720 & -809 & -916 & -587 & -732 & -857 & -953 \\
\hline Age class $65-80$ & -5526 & -6184 & -5713 & -5843 & -5178 & -5705 & -3944 & -3379 \\
\hline Age class $\geq 80$ & -7646 & -7599 & -4401 & -2122 & $-26,772$ & $-22,129$ & 12,515 & 21,932 \\
\hline Total age classes & $-13,716$ & $-14,503$ & $-10,922$ & -8882 & $-32,537$ & $-28,567$ & 7714 & 17,600 \\
\hline \multicolumn{9}{|c|}{ Net costs based on the VOLY } \\
\hline Age class $<65$ & -358 & -474 & -529 & -599 & -386 & -482 & -561 & -623 \\
\hline Age class $65-80$ & -1155 & -1292 & -1146 & -1172 & -1082 & -1192 & -791 & -678 \\
\hline Age class $\geq 80$ & -504 & -501 & -283 & -136 & -1764 & -1458 & 805 & 1411 \\
\hline Total age classes & -2017 & -2267 & -1958 & -1908 & -3233 & -3133 & -547 & 109 \\
\hline
\end{tabular}

that develop into net costs is consistent with the total net yearly mortality changes in Table 2 . Overall, the projections with the model for the total population underestimate net benefits in low warming scenarios in 2050 and fail to capture the net costs in high warming W scenarios in 2085, which illustrates the importance of using the more detailed differentiation of the mortality models based on age. Moreover, using the VOLY method results in smaller estimates of net benefits under low warming scenarios, and especially much lower net costs under the highest warming scenario. This can be explained by the VOLY method attaching a lower value to mortality savings in the cold and mortality losses in the heat for the highest age category that has a shorter remaining life expectancy.

\subsection{Adaptation and the economic impacts of mortality changes}

The substantial cost estimates reported in Table 3 illustrate the important economic gains that can be obtained from adaptation policies that reduce the negative impacts of warming on mortality, especially for the population group with age $\geq 80$ in particular, although such policies may also be beneficial for the other age classes. These adaptation policies, like improved air-conditioning, are likely to come at a cost and their desirability can be evaluated using a cost-benefit analysis in which the benefits can be derived from the prevented mortality losses based on our analysis here. Moreover, our findings regarding the importance of the urban heat island effect in future mortality losses highlight the relevance of implementing policies that limit local warming in urban areas, like urban greening. This observation is in line with findings by Jenkins et al. (2014) who conclude that such urban cooling measures can be effective in limiting heat-related mortality in London. Furthermore, it is important to highlight that in addition to mortality impacts from climate change, there may be significant morbidity impacts which are not studied here, but further justify the need for adaptation policies that limit health risk from climate change (Tong and Ebi 2019). 
Although our economic cost estimates indicate substantial gains from adaptation policies, and hence could serve as input for cost-benefit analyses to assess such policies, it should be realized that the mortality projections in Table 2 do not account for adaptation. The actual mortality changes in the future that will materialize will be smaller if adaptation occurs, as can be expected based on the findings from other studies. For instance, Barreca et al. (2015) find that between 1900 and 2004 such adaptation occurred in the USA, in a sense that impacts of extreme heat on mortality are smaller in states that more frequently experience extreme heat. Moreover, differences in the heat-mortality relationship between hot and cold states became smaller over this period, although they remained present. This is supported by evidence by Barreca et al. (2016) showing that the mortality impact of days with mean temperature exceeding $80{ }^{\circ} \mathrm{F}\left(26.7^{\circ} \mathrm{C}\right)$ declined by $75 \%$ over time. Kyselý and Plavcová (2012) observed that trends in mortality in the Czech Republic declined, despite rising temperatures. Geographically closer to the Netherlands is a study for France by Todd and Valleron (2015) who found that an increase in ambient temperature of $1.6^{\circ} \mathrm{C}$ between 1968 and 2009 was accompanied by an increase in the MMT of $0.8^{\circ} \mathrm{C}$, which suggests that adaptation occurred for about half of the temperature rise. Folkerts et al. (2020) find first evidence that such adaptation through an increase in the MMT also occurs in the Netherlands. They apply three methods to examine such a shift in the MMT in a period of 23 years for which two find a significant increase in the MMT that exceeds observed temperature rise, while one method finds no significant effect. Although these findings show adaptations in mortality patterns, this evidence is not fully conclusive. Moreover, it is questionable whether this high rate of adaptation observed in this short period can be sustained over the longer time period of our future mortality projections. This is why we do an exploratory analysis of how a stylized adaptation scenario in which the MMT increases by $50 \%$ of the temperature rise from climate change, influences our yearly mortality projections and monetization of these effects. The $50 \%$ adjustment is based on the findings by Todd and Valleron (2015), which although they are based on French data, reflect historical adjustments over a reasonable long time period that may be indicative of adaptation that could occur over the time horizons of our future projections. ${ }^{7}$

The mortality projections that account for adaptation in Table 4 show that adaptation is effective in reducing the number of additional deaths from global warming in the heat, which means larger net mortality reductions in all scenarios in which climate change is expected to reduce mortality without accounting for adaptation (Table 2). Moreover, the net mortality losses that occur in the high warming scenarios without adaptation can be prevented in our stylized adaptation scenario. The overall pattern of the total mortality changes in all age classes is that climate change combined with adaptation reduces yearly mortality at the end of the century the most under the low warming G scenarios, while this reduction is smaller if climate change is consistent with the high warming $\mathrm{W}$ scenarios. The monetary valuation of these impacts (also shown in Table 4) shows that net benefits of global warming from net reductions in mortality in 2050 are at maximum about $50 \%$ and $100 \%$ higher with adaptation based on the VOLY and VOSL approaches, respectively, compared with these estimates assuming no adaptation. Moreover, the substantial costs observed in 2085 under the high warming scenarios without adaptation can be turned into net benefits by adaptation. This finding that

\footnotetext{
${ }^{7}$ Some have assumed that adaptation does not only change the MMT but also increases cold sensitivity and reduces heat sensitivity (Huynen and Martens 2015). Results from Folkerts et al. (2020) based on the constrained segmented distributed lag model that is also applied in our study do not conclusively find that such changes in sensitivity occur in the Netherlands.
} 
adaptation can turn otherwise net mortality losses from climate change into net mortality benefits is not unique to our study, and has also been observed in a recent study by Heutel et al. (2020) for the USA.

\section{Discussion}

An important finding of our study is that climate change is expected to first decrease total net mortality in the Netherlands due to a dominant effect of less cold-related mortality, but this reverses over time under high warming scenarios that cause the increase in heat-related mortality to dominate. This dominance of heat-related mortality occurs in our projections for 2085 under both high warming scenarios if the urban heat island effect is considered, but not in the second highest warming scenario when the additional warming in the urbanized Randstad area is excluded. This observation highlights the importance of including the additional warming under climate change caused in cities by the urban heat island effect in studies that examine the potential effects of climate change on human mortality. In this respect, it should be noted that our estimate of the urban heat island effect on mortality should be seen as a lower bound, since we were not able to account for this effect for all Dutch cities, but focused on the main urbanized area in the Netherlands only. The reason is that for this area, we have estimates of both the urban heat island effect and demographic change under our adopted socioeconomic scenarios, while this information is not currently available for other cities. Nevertheless, our approach is an improvement compared with neglecting the urban heat island effect

Table 4 Projections of changes in total net yearly mortality and net economic costs of mortality in million euro losses per year as a result of climate change for the years 2050 and 2085 under different climate and socioeconomic scenarios, accounting for additional warming from the urban heat island (UHI) effect and adaptation, and using the VOSL or VOLY valuation method (negative values are net benefits, positive values are net costs)

\begin{tabular}{|c|c|c|c|c|c|c|c|c|}
\hline \multirow{3}{*}{$\begin{array}{l}\text { Climate change } \\
\text { scenario } \\
\text { Socio-economic } \\
\text { scenario }\end{array}$} & \multicolumn{4}{|l|}{ Year 2050} & \multicolumn{4}{|l|}{ Year 2085} \\
\hline & G & G+ & $\mathrm{W}$ & $\mathrm{W}+$ & G & $\mathrm{G}+$ & $\mathrm{W}$ & $\mathrm{W}+$ \\
\hline & $\begin{array}{l}\text { POP- } \\
\text { high }\end{array}$ & $\begin{array}{l}\text { POP- } \\
\text { high }\end{array}$ & $\begin{array}{l}\text { POP- } \\
\text { low }\end{array}$ & $\begin{array}{l}\text { POP- } \\
\text { low }\end{array}$ & $\begin{array}{l}\text { POP- } \\
\text { high }\end{array}$ & $\begin{array}{l}\text { POP- } \\
\text { high }\end{array}$ & $\begin{array}{l}\text { POP- } \\
\text { low }\end{array}$ & $\begin{array}{l}\text { POP- } \\
\text { low }\end{array}$ \\
\hline \multicolumn{9}{|c|}{ Total net impacts in terms of the change in number of deaths per year for } \\
\hline Total population & -1713 & -2032 & -2124 & -2341 & -2066 & -2423 & -2134 & -2228 \\
\hline Age class $<65$ & -80 & -104 & -119 & -133 & -85 & -107 & -127 & -141 \\
\hline Age class $65-80$ & -943 & -1137 & -1217 & -1307 & -935 & -1099 & -1225 & -1284 \\
\hline Age class $\geq 80$ & -1552 & -1828 & -1810 & -1917 & -6515 & -7324 & -3352 & -3121 \\
\hline Total age classes & -2575 & -3069 & -3146 & -3356 & -7535 & -8530 & -4704 & -4546 \\
\hline \multicolumn{9}{|c|}{ Net costs based on the VOSL } \\
\hline Total population & $-11,475$ & $-13,614$ & $-14,233$ & $-15,683$ & $-13,842$ & $-16,233$ & $-14,299$ & $-14,925$ \\
\hline Age class $<65$ & -536 & -699 & -794 & -889 & -572 & -714 & -852 & -947 \\
\hline Age class $65-80$ & -6319 & -7615 & -8156 & -8755 & -6266 & -7364 & -8207 & -8601 \\
\hline Age class $\geq 80$ & $-10,400$ & $-12,247$ & $-12,126$ & $-12,842$ & $-43,648$ & $-49,070$ & $-22,461$ & $-20,910$ \\
\hline Total age classes & $-17,255$ & $-20,560$ & $-21,077$ & $-22,486$ & $-50,486$ & $-57,149$ & $-31,519$ & $-30,458$ \\
\hline \multicolumn{9}{|c|}{ Net costs based on the VOLY } \\
\hline Age class $<65$ & -353 & -460 & -519 & -581 & -377 & -470 & -557 & -619 \\
\hline Age class $65-80$ & -1321 & -1592 & -1637 & -1757 & -1310 & -1539 & -1647 & -1726 \\
\hline Age class $\geq 80$ & -685 & -807 & -780 & -826 & -2877 & -3234 & -1445 & -1345 \\
\hline Total age classes & -2359 & -2859 & -2936 & -3164 & -4563 & -5243 & -3648 & -3690 \\
\hline
\end{tabular}


as has been done in several previous studies that examine the economic impacts of mortality changes under climate change (Deschênes and Greenstone 2011; Deschênes and Moretti 2009; Barreca 2012; Otrachshenko et al. 2017).

The economic valuation of the total net mortality changes indicates that climate change will first result in net benefits from the dominance of less cold-related mortality of up to $€ 2.3$ billion using the VOLY and $€ 14.5$ billion using the VOSL valuation method in 2050, while this changes over time in net economic costs under high warming scenarios of up to $€ 17.6$ billion in 2085 using the VOSL. In this respect, it is important to note the heterogeneity in economic impacts for mortality changes for the different age classes. Although climate change is expected to bring economic net benefits for mortality changes in age classes $<65$ and $65-$ 80 , it causes net economic costs for mortality changes in the age class $\geq 80$ under high warming scenarios, ranging from $€ 805$ million up to $€ 1.4$ billion based on the VOLY and ranging from 12.5 billion (W in 2085) up to $€ 21.9$ billion (W+ in 2085) based on the VOSL.

Even though our VOSL and VOLY estimates fall within the range of values reported in the literature (Hein et al. 2016), they are at the high end of these values and it should be noted that large uncertainties are associated with valuing losses of human life and human life years. For instance, Van Gils et al. (2014) indicate that VOSL and VOLY values for the Netherlands can also be up to $50 \%$ lower. Based on this lower bound, net benefits from mortality changes in 2050 range up to $€ 1.15$ billion using the VOLY and $€ 7.25$ billion using the VOSL valuation method, while the net costs under high warming scenarios reach up to $€ 8.8$ billion in 2085 using the VOSL. Even though this uncertainty in VOLY and VOSL has an important effect on our results, the largest differences in economic impacts arise between the application of either the VOLY and VOSL valuation method. The reason is that in our study, the largest mortality changes from climate change occur in the population group with age $\geq 80$, which has a relatively low remaining life expectancy and hence receives a low economic value using the VOLY approach. Although one could argue that preventing deaths of younger people is more valuable than preventing deaths of older people with fewer remaining life years, whether such an approach of giving lower values to mortality of older people is desirable or ethically justified may be debated. If an equal valuation of mortality across age classes is applied using the VOSL method, then an implication is that estimated mortality benefits in low warming scenarios and estimated mortality costs in high warming scenarios are substantially higher.

In comparison with other studies, our study is the closest to Daanen et al. (2013) who made a first attempt to estimate the impacts of climate change on mortality in the Netherlands based on a regression model of mortality in the total population, assuming neither future demographic change nor time lags. They estimated net benefits from mortality changes as a result of climate change between $€ 12$ million and $€ 25$ million for four climate change scenarios due to less cold-related mortality, which can increase with $€ 8$ million if additional warming from the urban heat island effect is included. In our study, we find substantially higher net benefits for low warming scenarios and net costs for high warming scenarios, which apart from using a higher Dutch VOSL value can be explained by the following four main methodological differences. First, we account for the time lags in temperature effects on mortality and our results show that the summed effects over time are much larger than only the instant effect (see Supplementary Material 3). Second, we separately estimate the impacts of temperature changes in the cold and heat and find that people are especially vulnerable to heat conditions, which will occur more frequently under climate change. Third, we estimate the effects of temperature on mortality for different age classes and find that older age groups are more vulnerable to cold and heat stress, and that the sum of the mortality changes under warming 
scenarios often exceeds mortality changes based on a model of mortality in the total population. Fourth, we account for demographic change, namely, population growth, ageing of the population and trends in urbanization. Ageing of the population has an important influence on our mortality projections, because increased heat results in especially higher mortality when there are more old people that appear to be the most vulnerable to heat. Overall, our results highlight the usefulness of modelling time lags, accounting for differences in vulnerability to temperature increases between age classes, and including demographic change when estimating future impacts of climate change on mortality.

\section{Conclusion}

Climate change is expected to increase the frequency and severity of heat stress and reduce the frequency and severity of cold stress, which can have large implications for human health and mortality in particular. This study has obtained insights into the potential impacts of climate change on mortality in the Netherlands, which is currently experiencing mainly cold-related mortality, and the associated economic costs. Our methods account for changes in both cold and heat-related mortality for different age classes, the time dynamics associated with temperature-related mortality, demographic change and the urban heat island effect.

Our statistical modelling results show that heat and cold impacts on mortality vary considerably between age classes, in a way that older segments of the population are more vulnerable to extreme heat and cold conditions. This finding underlines the relevance of accounting for demographic change and, in particular, the ageing of the population in estimating the impacts of climate change on future mortality. Moreover, we find that sensitivity of mortality to temperature is much higher on hot than cold days for the most vulnerable age group, and that extreme temperature conditions appear to have long time lags on mortality, especially in cold periods. These observations support our use of the constrained segmented distributed lag model that accounts for these time dynamics and different susceptibility to heat and cold stress.

A main finding of our study is that climate change is expected to first decrease total net mortality in the Netherlands due to a dominant effect of lowered cold-related mortality, but this reverses over time under high warming scenarios. A dominance of more heat-related mortality occurs in our projections for 2085 under both of our high warming scenarios if the urban heat island effect is considered, but is less pronounced when the additional warming in the urbanized Randstad area is not accounted for. This observation highlights the importance of including the additional warming under climate change caused in cities by the urban heat island effect in studies that examine the potential effects of climate change on human mortality. The economic valuation of the total net mortality changes indicates that climate change will first result in net benefits from the dominance of less cold-related mortality of up $€ 2.3$ billion using the VOLY and $€ 14.5$ billion using the VOSL valuation method in 2050 , while this changes over time in net economic costs under high warming scenarios of up to $€ 17.6$ billion in 2085 using the VOSL. This implies that high economic gains can be obtained by implementing adaptation policies that reduce the negative impacts of warming on mortality, especially for the old segment of the population for which mortality losses are the highest in absence of additional policies. Our exploratory analysis of future expected mortality changes and related economic impacts under a stylized adaptation scenario in which historical adaptation continues in the future suggests that such adaptation is highly effective, and could even 
prevent net costs from occurring in high warming climate change scenarios. Whether such trends in reduced vulnerability to heat can be sustained in the future under climate change is highly uncertain, but an important topic for future research. In particular, it would be especially useful if such future studies could assess which adaptation measures are most effective in limiting heat-related mortality, and how such measures can be effectively promoted through adaptation policies considering societal stimuli and barriers (Runhaar et al. 2012). In this respect, it is important to note that adaptation measures for attenuating cold-related deaths are likely to differ from those for reducing heat-related deaths.

Funding information This study is funded by the Amsterdam Sustainability Institute and the European Union's Horizon 2020 research and innovation programme under grant agreement no 776479.

Open Access This article is licensed under a Creative Commons Attribution 4.0 International License, which permits use, sharing, adaptation, distribution and reproduction in any medium or format, as long as you give appropriate credit to the original author(s) and the source, provide a link to the Creative Commons licence, and indicate if changes were made. The images or other third party material in this article are included in the article's Creative Commons licence, unless indicated otherwise in a credit line to the material. If material is not included in the article's Creative Commons licence and your intended use is not permitted by statutory regulation or exceeds the permitted use, you will need to obtain permission directly from the copyright holder. To view a copy of this licence, visit http://creativecommons.org/licenses/by/4.0/.

\section{References}

Baccini M, Biggeri A, Accetta G, Kosatsky T, Katsouyanni K, Analitis A, Anderson HR, Bisanti L, D'iippoliti D, Danova J, Forsberg B, Medina S, Paldy A, Rabczenko D, Schindler C, Michelozzi P (2008) Heat effects on mortality in 15 European cities. Epidemiology 19:711-719

Barreca AI (2012) Climate, humi,dity, and mortality in the United States. J Environ Econ Manag 63:19-34

Barreca AI, Clay K, Deschênes O, Greenstone M, Shapiro JS (2015) Convergence in adaptation to climate change: evidence from high temperatures and mortality, 1900-2004. Am Econ Rev 105(5):247-251

Barreca AI, Clay K, Deschênes O, Greenstone M, Shapiro JS (2016) Adapting to climate change: the remarkable decline in the U.S. temperature- mortality relationship over the 20th century. J Polit Econ 124(1):105-159

Daanen HAM, Jonkhoff W, Bosch P, Ten Broeke H (2013) The effect of global warming and urban heat islands on mortality, morbidity and productivity in The Netherlands. ICEE conference proceedings. Queenstown, New Zealand. Pages 16-19. ISBN978-0-473-22821-7

Deschênes O, Greenstone M (2011) Climate change, mortality, and adaptation: evidence from annual fluctuations in weather in the US. Am Econ J Appl Econonomics 3(4):152-185

Deschênes O, Moretti E (2009) Extreme weather events, mortality, and migration. Rev Econ Stat 91(4):659-681

Estrada F, Botzen WJW, Tol R (2017) A global economic assessment of city policies to reduce climate change impacts. Nat Clim Chang 7:403-406

Folkerts MA, Bröde P, Botzen WJW, Martinius ML, Gerrett N, Harmsen CN, Daanen HAM (2020) Long term adaptation to heat stress: shifts in the minimum mortality temperature in the Netherlands. Front Physiol 11: 225

Hein AL, Roberts P, Gonzalez L (2016) Valuing a statistical life year in relation to clean air. J Environ Assess Policy Manag 18(4):1-4

Heutel G, Miller NH, Molitor D (2020) Adaptation and the mortality effects of temperature across U.S. regions. Rev Econ Stat (in press)

Huber V, Ibaretta D, Frieler K (2017) Cold- and heat-related mortality: a cautionary note on current damage functions with net benefits from climate change. Clim Chang 142(3-4):407-418

Huynen MMTE, Martens P (2015) Climate change effects on heat- and cold-related mortality in the Netherlands: a scenario-based integrated environmental health impact assessment. Int J Environ Res Public Health 12(10): $13295-13320$

IPCC (2013) Climate change 2013: the natural science basis. Contribution of working group I to the fifth assessment report of the intergovernmental panel on climate change [T.F. Stocker, D. Qin, G.-K. Plattner, 
M.M.B. Tignor, S.K. Allen, J. Boschung, A. Nauels, Y. Xia, V. Bex and P.M. Midgley (eds)], Cambridge, U.K: Cambridge University Press

IPCC (2014) Climate Change 2014: Impacts, adaptation, and vulnerability. Part A: global and sectoral aspects. Contribution of working group II to the fifth assessment report of the intergovernmental panel on climate change [Field, C.B., V.R. Barros, D.J. Dokken, K.J. Mach, M.D. Mastrandrea, T.E. Bilir, M. Chatterjee, K.L. Ebi, Y.O. Estrada, R.C. Genova, B. Girma, E.S. Kissel, A.N. Levy, S. MacCracken, P.R. Mastrandrea, and L.L.White (eds.)]. Cambridge University Press, Cambridge, United Kingdom and New York, NY, USA, $1132 \mathrm{pp}$

Jenkins K, Hall J, Glenis V, Kilsby C, McCarthy M, Goodess C, Smith D, Malleson N, Birkin M (2014) Probabilistic spatial risk assessment of heat impacts and adaptations for London. Clim Chang 124(1-2):105117

Karl TR, Diaz HF, Kukla G (1988) Urbanization: its detection and effect in the United States climate record. J Clim 1:1099-1123

Klein Tank A, Beersma J, Bessembinder J, van den Hurk B, Lenderink G (2014) KNMI'14 klimaatscenario's voor Nederland-Leidraad voor professionals in Klimaatadaptatie [climate scenarios for Netherlandsguidance for climate adaptation professionals], De Bilt, the Netherlands: Royal Netherlands Meteorological Institute (KNMI)

Kunst AE, Looman, CWN, Mackenbach JP (1993) Outdoor air temperature and mortality in the Netherlands: A time-series analysis. Am J Epidemiol 137(3):331-341

Kyselý J, Plavcová E (2012) Declining impacts of hot spells on mortality in the Czech Republic, 1986-2009: adaptation to climate change? Clim Chang 113(2):437-453

Longden T (2019) The impact of temperature on mortality across different climate zones. Clim Chang https://doiorg.vu-nl.idm.oclc.org/10.1007/s10584-019-02519-1

Manders T, Kool C (2015) Toekomstverkenning Welvaart en Leefomgeving Nederland in 2030 en 2050: twee referentiescenario's. Planbureau voor de Leefomgeving en Centraal Planbureau, Den Haag

Marsha A, Sain SR, Heaton MJ, Monaghan AJ, Wilhelmi OV (2018) Influences of climatic and population changes on heat-related mortality in Houston, Texas, USA. Clim Chang 146(3-4):471-485

Mills G (2014) Urban climatology: history, status and prospects. Urban Clim 10:479-489

Mills D, Schwartz J, Lee M, Sarofim M, Jones R, Lawson M, Duckworth M, Deck L (2015) Climate change impacts on extreme temperature mortality in select metropolitan areas in the United States. Clim Chang 131(1):83-95

Muggeo VMR (2008) Modeling temperature effects on mortality: multiple segmented relationships with common break points. Biostatistics 9:613-620

Muggeo VMR (2010) Analyzing temperature effects on mortality within the R environment: the constrained segmented distributed lag parameterization. J Stat Softw 32(12):1-17

Oke TR (1973) City size and the urban heat island. Atmos Environ. Pergamon Press 7:769-779

Otrachshenko V, Popova O, Solomin P (2017) Health consequences of the Russian weather. Ecol Econ 132:290306

Patz JA, Campbell-Lendrum D, Holloway T, Foley JA (2005) Impact of regional climate change on human health. Nature 438:310-317

Runhaar H, Mees H, Wardekker A, van der Sluijs J, Driessen PPJ (2012) Adaptation to climate change-related risks in Dutch urban areas: stimuli and barriers. Reg Environ Chang 12(4):777-790

Sheridan SC, Allen MJ, Lee CC, Kalkstein LS (2012) Future heat vulnerability in California, part II: projecting future heat-related mortality. Clim Chang 115(2):311-326

Stern N (2007) The economics of climate change: the Stern review. Cambridge Univ. Press

Todd N, Valleron AJ (2015) Space-time covariation of mortality with temperature: a systematic study of deaths in France, 1968-2009. Environ Health Perspect 123:659-664

Tong S, Ebi K (2019) Preventing and mitigating health risks of climate change. Environ Res 174:9-13

Van Gils PF, Schoemaker C, Polder JJ (2014) Hoeveel mag een gewonnen levensjaar kosten?: Onderzoek naar de waardering van de QALY. Nederlandsch Tijdschrift voor Geneeskunde 157(52):A6507

Watkiss P, Hunt A (2012) Projection of economic impacts of climate change in sectors of Europe based on bottom up analysis: human health. Clim Chang 112:101-126

Zhao L, Lee X, Smith RB, Oleson K (2014) Strong contributions of local background climate to urban heat islands. Nature 511:216-219

Publisher's note Springer Nature remains neutral with regard to jurisdictional claims in published maps and institutional affiliations. 


\section{Affiliations}

W. J. W. Botzen ${ }^{1,2} \cdot$ M. L. Martinius ${ }^{3} \cdot$ P. Bröde ${ }^{4} \cdot$ M. A. Folkerts ${ }^{5} \cdot$ P. Ignjacevic ${ }^{1} \cdot$ F. Estrada $^{1,6} \cdot$ C. N. Harmsen ${ }^{7} \cdot$ H. A. M. Daanen ${ }^{5}$

1 Institute for Environmental Studies (IVM), Vrije Universiteit Amsterdam, De Boelelaan 1087, 1081 HV Amsterdam, The Netherlands

2 Utrecht University School of Economics (U.S.E.), Utrecht University, Utrecht 3508 TC, The Netherlands

3 Institute for Interdisciplinary Studies (IIS), University of Amsterdam, Amsterdam, The Netherlands

4 Leibniz Research Centre for Working Environment and Human Factors (IfADo), Dortmund, Germany

5 Department of Human Movement Sciences, Faculty of Behavioural and Movement Sciences, Vrije Universiteit Amsterdam, Amsterdam Movement Sciences, Van der Boechorststraat 7, Amsterdam 1081 BT, The Netherlands

6 Centro de Ciencias de la Atmósfera, Universidad Nacional Autónoma de México, 04510 Mexico City, Mexico

7 Statistics Netherlands, The Hague, The Netherlands 